\title{
Influence of blending proportions of Teak Sawdust and Cajuput leaves on characteristics of biomass pellets
}

\author{
Wassachol Wattana ${ }^{1 *}$, Nattaya Montri $^{2}$, Manussavee Wongjanakul ${ }^{1}$, Yingyot Naratta $^{1}$, and \\ Sansanee Duangjinda ${ }^{1}$ \\ ${ }^{1}$ KMITL Prince of Chumphon Campus, Mechanical Engineering Department, 17/1 M.6 Chumkho \\ Pathiu Chumphon, Thailand \\ ${ }^{2}$ KMITL Prince of Chumphon Campus, Technology Management for Plant Production Department, \\ 17/1 M.6 Chumkho Pathiu Chumphon, Thailand
}

\begin{abstract}
Fuel pellets made from biomass is considered as a solid fuel that is also an alternative fuel which can substitute for the current fuels and can be considered as a fuel that has sustainable production. This research is the study of the production of fuel pellets from Teak sawdust blends with Cajuput leaves at five proportions by weight of Teak sawdust $100 \%$, Cajuput leaves $100 \%$, Teak sawdust $75 \%$ +Cajuput leaves $25 \%$, Teak sawdust $50 \%$ + Cajuput leaves $50 \%$, Teak sawdust $25 \%$ +Cajuput leaves $75 \%$. The pellets were produced by a grinding and pelleting machine at three different speeds of 200,250 , and $300 \mathrm{rpm}$. After that, the quality of fuel pellets was evaluated by the physical properties as pellet dimensions, particles and bulk density, as well as moisture content and durability. The results show that blending proportion of Teak sawdust $75 \%$ and Cajuput leaves $25 \%$ provided the appropriate fuel pellet properties.
\end{abstract}

\section{Introduction}

Wood is the primary source for solid fuel, however, nowadays the number of trees has decreased dramatically. To reduce the deforestation, sustainable woody biomass sources like agro-residues, leaf litter, herbaceous biomass or waste from wood processing were offered. However, those raw biomasses have an improper solid fuel as high moisture content, irregular size and shape and low bulk density. These cause problems with storage, transportation and combustion efficiency. To solve these problems, densification is the favoured technique in which biomass is compressed to dense biomass in uniform shapes. Biomass pellets is a satisfied densification form due to various useable and direct combustion in a stove or boiler, co-firing with coal and used in power plants or solid fuel in the gasification process [1]. The many blends of raw biomass were studied to improve the properties of fuel pellets. Jatropha shell waste blended with Seed cake biochar was explored for the opportunity for producing pellets. The mixture of Seed cake biochar and Jatropha shell of 100, 75, 50, 25 and $0 \%$ each, particle sizes of 2 and $4 \mathrm{~mm}$, and amount of adding water of $15 \%$ and $25 \%$ were evaluated.

* Corresponding author: wassachol.wa@,kmitl.ac.th 
The $9 \mathrm{~mm}$ diameter and $2 \mathrm{~cm}$ length pellets were produced by a semi industrial pelletizer. Pellet blends of $50 \%$ Jatropha shell and $50 \%$ Seed cake biochar, with $25 \%$ of additional water and a $4 \mathrm{~mm}$ particle size, provided the greatest mechanical durability $(96.83 \%)$, and higher heating value $(22.14 \mathrm{MJ} / \mathrm{kg})$ [2]. The fuel pellet made from rice husk mixed with wheat straw with a modified pellet machine in $6 \mathrm{~mm}$ diameter and $22 \mathrm{~mm}$ length. The raw biomass was homogenized using a 250-micron mesh and mixed using three proportions, 100:0, 50:50 and $75: 25$ of rice husk and wheat straw with 21 and $23 \%$ of initial moisture. The physicochemical and energetic characterization of pellets were carried out and compared with the ISO 172256 standard. The rice husk pellets provided the lowest calorific value and highest ash content, while the blended pellet provided improved quality with higher calorific value and reduced the ash content. The results confirmed that the biomass blends can enhance the pellet properties [3]. Co-pelletization of Chlorella vulgaris and Pine sawdust properties were evaluated at different proportions of $0,25,50,75$, and $100 \%$. The microalgae was dried to a $10 \% \mathrm{wb}$. moisture content whereas Pine sawdust were milled and screened to $3.2 \mathrm{~mm}$ and adding water to receive a $10 \% \mathrm{wb}$. moisture content. The proximate and ultimate analysis and calorific value of raw materials was determined. The pellet produced from a single pelletizer with a $6.35 \mathrm{~mm}$ diameter. Adding microalgae to sawdust can help in decreasing of densification energy and can improve the pellets properties. The testing of densification was carried out at 50,75 , and $100^{\circ} \mathrm{C}$ and compression force from 2500 to $3500 \mathrm{~N}$. The pure microalgae pellet has higher durability than pure sawdust, also, similar trends occurred in pellet density, porosity, expansion, and moisture absorption. The results of the data indicated that the durability of adding microalgae pellets were received at moderate densification temperatures and force [4].

The Teak sawdust is the residues from the wood processing where the Cajuput is the local tree in swamp forests. The swamp forests area is very small compared to the total forest area, resulting in a chance that the Cajuput tree to become extinct. The use of the Cajuput has one method that can help increase the chances of reproduction of the tree. There are studies that indicate that the leaves of the Cajuput tree have an essential oil [5] which indicates that it could possibly be used as fuel. Teak is the commercial tree of Northern Thailand however, if you can create additional incentives to utilize it, there will be an increased little planting area in the other regions of Thailand. The wood sawdust is the main raw material that use to produce pellet and the Cajuput leaves is selected to improve the fuel properties. The reason for this study is to use the Cajuput leaves to blend with Teak sawdust to produce the fuel pellet. The aim of this study is to characterize the blending of two types of forestry biomass to produce fuel pellets then compare with the standard EN 14961-1 [6]. Fuel pellets were produced at five proportions of Teak sawdust (TS) blends with Cajuput leaves (CL) and three pelleting speeds.

\section{Material and method}

\subsection{Methods}

Teak sawdust (Figure 1a) was received from Forest Industry Organization (FIO) and sundried for one day that reduced the moisture down to $32-36 \% \mathrm{wb}$. because of the pellet can forming in this range of moisture content and then kept in a sealed package. The Cajuput leaves were collected from KMITL, Prince of Chumphon campus farm and sun-dried for two days (Figure 1.b) which reduced the moisture to the same level of Teak sawdust. After that, the two materials were weighed for each mixing proportion and the total equal to one kilogram. The biomass pellets were produced by using the grinding and pelleting machine at the laboratory as shown in Figure 2. The mixed raw materials were reduced to smaller sizes 
in the grinding section and passed the screen through the pelletizer part that the grinding of raw materials were forced past the die by roller to form the cylindrical pellet.
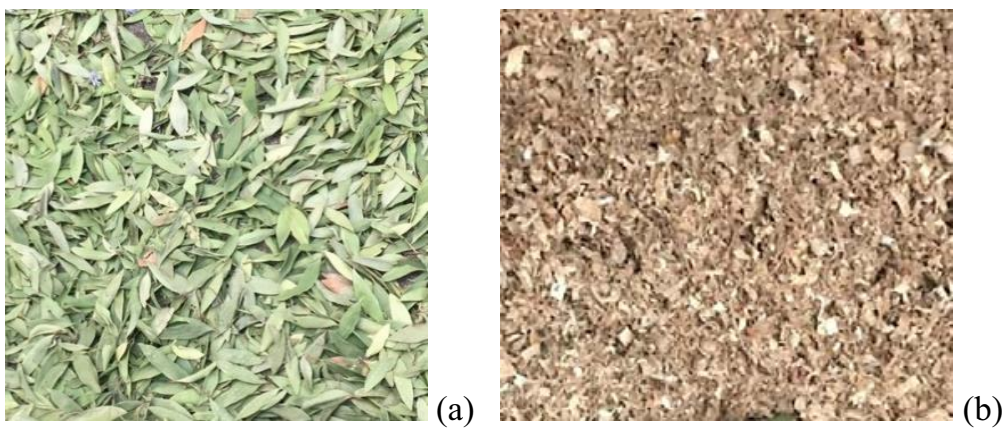

Fig. 1. (a) Cajuput leaves and (b) Teak sawdust.

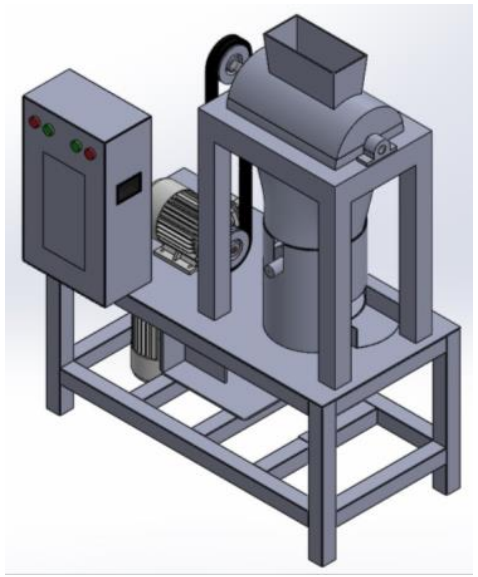

Fig. 2. Schematic of grinding and pelleting machine.

\subsection{Experimental procedure}

The effects of mixing proportion between Teak sawdust and Cajuput leaves and die speed were determined during the experiments. The mixing proportions were prepared to 5 proportions as 100:0, 75:25, 50:50, 25:75, and 0:100\% by weight of Teak sawdust (TS): Cajuput leaves (CS). All raw material conditions were examined of fuel properties as proximate analysis through the thermogravimetry analysis (Pyris1 TGA, Perkin Elmer) to indicate the moisture, ash, volatile matter, and fixed carbon content of the raw material in percent by weight $(\% \mathrm{wt}$.). The biomass pellets of each conditions were characterized via physical properties as, pellet length and diameter, bulk and particle density, strengthen, and durability. The length, diameter, and weight of each condition of pellets were measured by a digital Vernier calliper and $0.001 \mathrm{~g}$ resolution of electronic balance from 10 pellet samples. The particle density was calculated from the proportion between each pellets' weight and their volume. The volume of the pellet was calculated from its length and diameter as cylinder volume. The bulk density was determined according to EN15103 standard [7] in which the cylindrical vessel was filled up with pellets that drop from $30 \mathrm{~cm}$ in height until the maximum level of pellets in the vessel was reached. Then, the vessel was tapped 3 times to settle the pellets in the vessel and the excess pellets from the edges of the vessel were removed by a ruler. The bulk density was calculated by proportion of all the remaining pellets weight in the 
vessel to its volume and repeat three time for each condition. The strengthen of pellet was examined via the maximum force that horizontal pellet is broken from three pellet samples. Pellet durability was accomplished as given in DIN EN ISO17831-1:2016 [8] in which 500 $\mathrm{g}$ of pellet samples was tumbled in a dense tumbler that rotated at $50 \mathrm{rpm}$ for $10 \mathrm{~min}$. The durability was calculated from the percentage proportion of the remaining mass of pellets after tumbling to the mass of pellets before tumbling with three duplicates for each condition.

\section{Results and discussion}

\subsection{Proximate analysis and heating value of raw material}

The raw materials were examined in the proximate analysis and high heating value (HHV) to evaluate the fuel properties that show in Table 1. All thermogravimetric experiments were heated from room temperature to $900^{\circ} \mathrm{C}$ with a rate of $15^{\circ} \mathrm{C} / \mathrm{min}$ under the air atmosphere with two duplicates at each condition. The all HHV values received from oxygen bomb calorimeter (IKA, Model C1) according to DIN 51900-1 with three duplicates for each condition.

Table 1. Proximate analysis and high heating value of raw materials.

\begin{tabular}{|c|c|c|c|c|c|}
\hline Raw materials & $\begin{array}{c}\text { Moisture, } \\
\text { \%wt. }\end{array}$ & $\begin{array}{c}\text { Volatile } \\
\text { matter,\%wt. }\end{array}$ & $\begin{array}{c}\text { Fixed } \\
\text { carbon,\%wt }\end{array}$ & $\begin{array}{c}\text { Ash, } \\
\% \text { wt. }\end{array}$ & $\begin{array}{c}\mathrm{HHV}, \\
\mathrm{MJ} / \mathrm{kg}\end{array}$ \\
\hline TS100 \% & 8.130 & 60.720 & 30.447 & 0.703 & 19.16 \\
\hline CL100 \% & 6.642 & 55.104 & 43.587 & 3.667 & 20.08 \\
\hline CL75 \% + TS25 \% & 7.276 & 58.343 & 32.031 & 2.35 & 20.07 \\
\hline CL50 \% + TS50 \% & 7.017 & 58.824 & 31.632 & 2.527 & 19.66 \\
\hline CL25 \% + TS75 \% & 7.855 & 78.681 & 12.042 & 1.422 & 19.34 \\
\hline
\end{tabular}

Suitable fuel should have high fixed carbon content and low moisture and ash content. The results from the proximate analysis show that CL100\% provides the highest fixed carbon content of $43.587 \%$ wt. while TS100\% merely contained $30.447 \%$ wt. The amount of fixed carbon was decreased when the proportion of Cajuput leaves decreased. It was found that the fixed carbon content of these pellets was higher than lignite coal [9] and other waste biomass such as Camellia seed husk [10] palm kernel cake [11] microalgae [12] fibers and coconut husk shells [13]. Moreover the ash content received is lower than all of the above mentioned biomass. The Cajuput leaves provided better high heating value when compared with Teak sawdust, however it was insignificantly different.

\subsection{Physical properties}

\subsubsection{Pellet Dimension}

Because the die diameter of the pellet machine is $8 \mathrm{~mm}$, the resulting biomass pellet size is $8.42-8.87 \mathrm{~mm}$. All of the obtaining biomass pellets (Figure 3 ) were larger than $8 \mathrm{~mm}$ due to expansion after pelletization. It was found that the diameter of the biomass pellets were slightly larger than the standard EN 14961-1 [6] which is set to be in the range of 6-8 mm. The length of the biomass pellet was in the range of 10-29 mm, in line with EN 14961-1 [6] 
which was defined at 15-40 mm. It is also consistent with M. Barbanera's research [14], in which olive mill husks were compressed to pellets in the lengths between 20-24 mm. The best length is obtained from the proportion of TS $50 \%$ and CL $50 \%$ at the speed of $250 \mathrm{rpm}$ pelletizing.

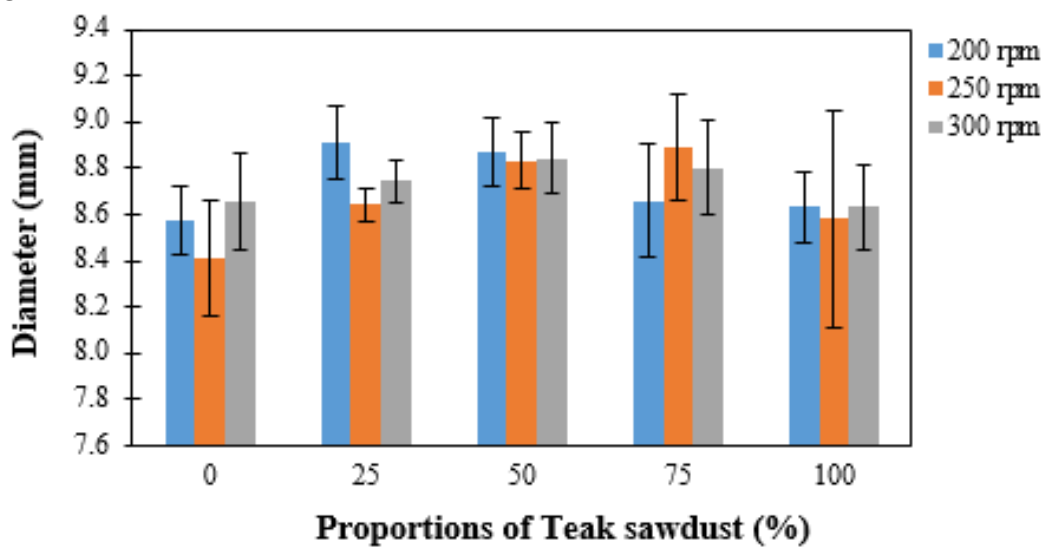

Fig. 3. Pellet diameter at various proportions of teak sawdust and pelleting speed.

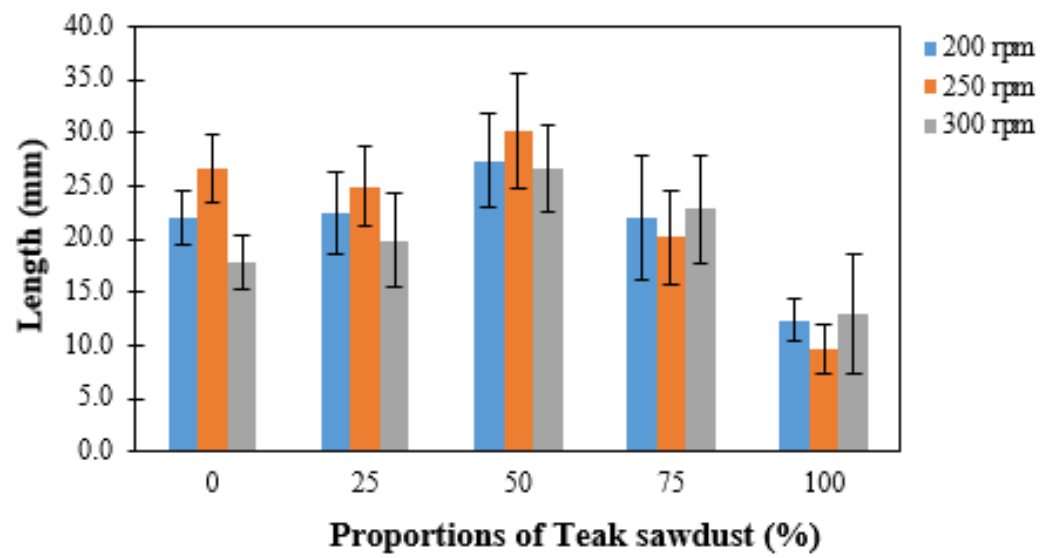

Fig. 4. Pellet length at various proportions of teak sawdust and pelleting speed.

From Figure 3, it can be seen that, there are resemblances when increasing the proportion of TS $25 \%$ to $100 \%$ at each speed. At the proportion of CL $100 \%$ with a speed of $250 \mathrm{rpm}$, the diameter is less than at a speed of 200,300 rpm. Because the Cajuput leaves have more fiber content than Teak sawdust, leading to more adhesion force during pelletization at the appropriate speed. The length of the pellet at each condition was shown in Figure 4. It was found that, at the proportion of CL 75\%:TS 25\% for all pelleting speeds provided the insignificant difference in length of biomass pellets. However, when the proportion of teak sawdust was increased, the length of the pellet decreased. It was observed that at CL $100 \%$, the pelleting speed provided the longest length of the pellet, which was $250 \mathrm{rpm}$ similarly for the result of pellet diameter. At higher speed, it will cause the pellet to break quickly. All the pellets lengths were between 10.42-29.09 mm that followed in EN 14961-1 (15-40 mm) [6]. 


\subsubsection{Pellet density}

The results of pellet density is shown in two types, the density of the one pellet or particle density (Figure 5) and the density of pellets in the container or bulk density (Figure 6). The standard value of particle and bulk density is more than $1000 \mathrm{~kg} / \mathrm{m}^{3}$ and $600 \mathrm{~kg} / \mathrm{m}^{3}$, respectively [7]. The particle and bulk density of pellets from Teak sawdust and Cajuput leaves in this study were ranged approximately between $500-800 \mathrm{~kg} / \mathrm{m}^{3}$ and $200-400 \mathrm{~kg} / \mathrm{m}^{3}$ respectively. These values were lower than the standard value because of the performance of the pellet machine or sizing of the raw materials.

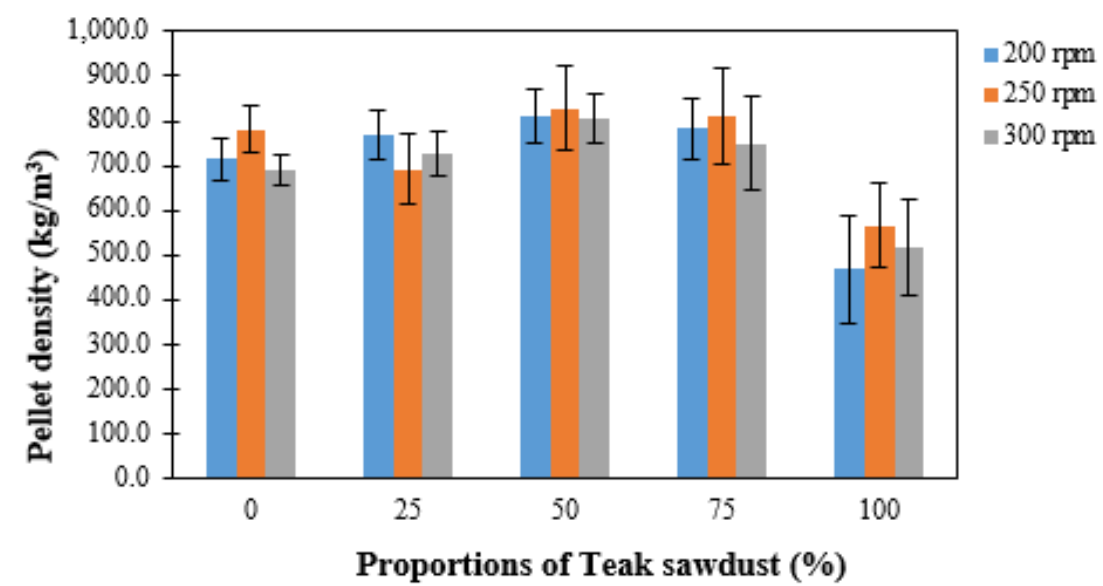

Fig. 5. Pellet density at various proportions of teak sawdust and pelleting speeds.

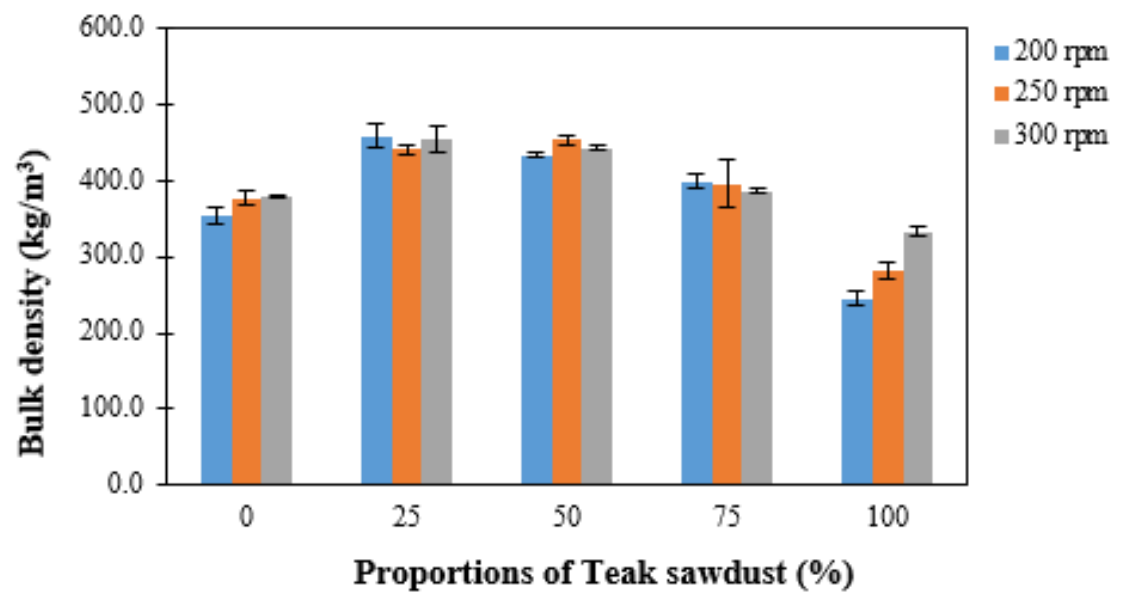

Fig. 6. Pellet bulk density at various proportions of teak sawdust and pelleting speeds.

The pellet density was shown in Figure 5, CL 100\% of the highest density was received from $250 \mathrm{rpm}$ of pelleting speed that complied with the dimension results. But for the TS $100 \%$, the pellet density is less than other proportions. They are slightly different than the pellet density from all proportions. 


\subsubsection{Pellet strengthen}

The maximum force that broken the horizontal pellets were presented in Figure 7. The condition of TS $100 \%$ is the most weakness pellet because of the water content in sawdust was insufficient to be binding agent between sawdust particles. The moisture in sawdust was easier evaporated than that is in the Cajuput leaves. The best condition was recieved from TS $25 \%$ blend with CS $75 \%$. The higher pelleting speed was provided the more strengthen pellet.

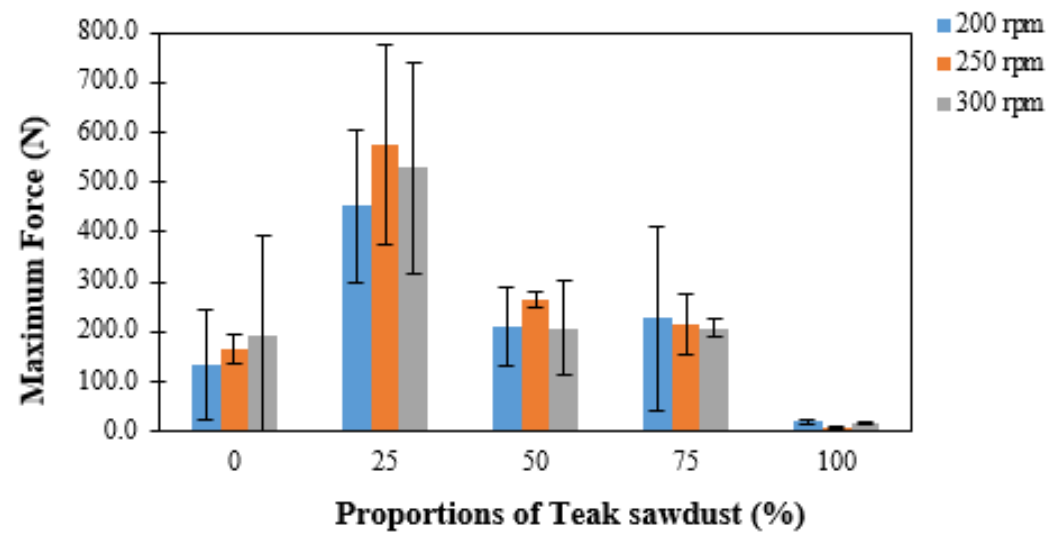

Fig. 7. Maximum force where the pellet broken at various proportion of teak sawdust and pelleting speed.

\subsubsection{Pellet durability}

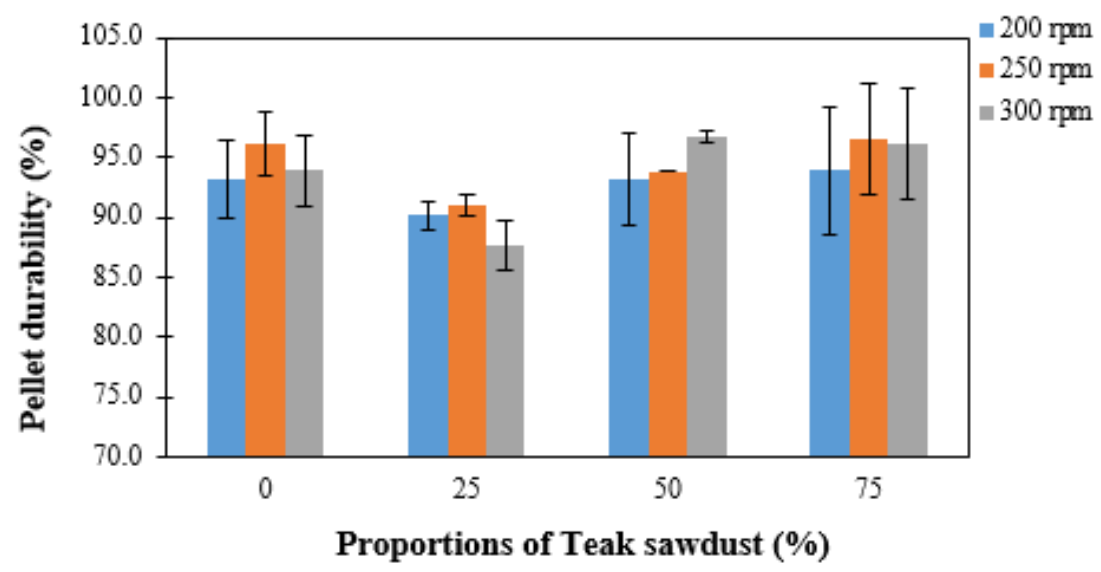

Fig. 8. Pellet durability at various proportions of teak sawdust and pelleting speeds.

From the results of pellet durability, that are shown in Figure 8, could not include the durability from TS $100 \%$ pellet because all of them were not strong enough for durability testing which corresponding to result of maximum force as shown in Figure.7. The results indicated the pellet durability was in the range of $87.64-96.76 \%$ where the EN14961-2 required more than $97.5 \%$ [14]. The best durability was received from $50 \%$ Cajuput leaves blended with $50 \%$ Teak sawdust at the pelleting speed of $300 \mathrm{rpm}$. 


\section{Conclusions}

Fuel pellets made from Teak sawdust blends, with Cajuput leaves at five proportions, the physical properties were evaluated. Increase in the proportion of Teak sawdust will cause increased durability of the fuel pellet. From the overall results of this study, it was found that the optimum proportion is $25 \%$ TS blend with $75 \% \mathrm{CL}$ at $250 \mathrm{rpm}$ pelleting speed. The blending of Cajuput leaves can help improve physical properties of Teak sawdust. The moderate speed of pelleting was preferred more than the high speed. The substitution of Cajuput leaves can enhance the high heating value of biomass pellet made from only feedstocks as wood sawdust. The all results of this study indicate opportunity to use Cajuput leaves as feedstocks to modify the pellet quality.

The authors gratefully acknowledge the financial support provided by Plant Genetics Conservation Project under The Royal Initiative of Her Royal Highness Princess Maha Chakri Sirindhron; The conservation and sustainable utilization of Melaleucacajuputi Powell: The study on local wisdom, propagation, secondary compounds from Melaleucacajuputi Powell leaves and product development for commercial purpose ; Fuel pellet production from teak sawdust and cajuput leaves was supported by 2018 Government Budget Grant.

\section{References}

1. N. Kalivan and R.V. Morey, Biomass Bioenergy 33, 337 (2009)

2. V. Ramírez, J. Martí-Herrero, M. Romero, and D. Rivadeneira, Journal of Cleaner Production 215, 1095 (2019)

3. I. M. Ríos-Badrán, I. Luzardo-Ocampo, J. F. García-Trejo, J. Santos-Cruz, and C. Gutiérrez-Antonio, Renewable Energy 145, 500 (2020)

4. H. Hosseinizand, S. Sokhansanj, and C. J. Lim, Fuel Processing Technology 177, 129 (2018)

5. A. W. Ismanto, H. S. Kusuma, M. Mahfud, MATEC Web of Conferences 156, 03007 (2018)

6. I. Obernberger and G. Thek, The Pellet Handbook: The Production and Thermal Utilisation of Pellets (Routledge, 2010)

7. E. Alakangas, European Standards for Fuel Specification and Classes of Solid Biofuels, edited by P. Grammelis (Green Energy and Technology. Springer, London, 2011)

8. R. Labbé, S. Paczkowski, V. Knappe, M. Russ, M. Wöhler, and S. Pelz, Fuel 263, $116662(2020)$

9. E. R. Widjaya, G. Chen, L. Bowtell, and C. Hills, Renewable and Sustainable Energy Reviews 89, 184 (2018)

10. M. Tan, L. Luo, Z. Wu, Z. Huang, J. Zhang, J. Huang, Y. Yang, X. Zhang, and H. Li, Fuel Processing Technology 201, 106337 (2020)

11. R. Razuan, K.N. Finney, Q. Chen, V.N. Sharifi, and J. Swithenbank, Fuel Processing Technology 92, 609 (2011)

12. M.T. Miranda, F.J. Sepúlveda, J.I. Arranz, I. Montero, and C.V. Rojas, Fuel 226, 121 (2018)

13. Z. Liu, A. Quek, and R. Balasubramanian, Applied Energy 113, 1315 (2014)

14. M. Barbanera, E. Lascaro, V. Stanzione, A. Esposito, R. Altieri, and M. Bufacchi, Renewable Energy 88, 185 (2016) 